\title{
Comparative effectiveness of liraglutide in the treatment of type 2 diabetes
}

This article was published in the following Dove Press journal:

Diabetes, Metabolic Syndrome and Obesity:Targets and Therapy 18 March 2014

Number of times this article has been viewed

\author{
Mauro Rigato \\ Gian Paolo Fadini \\ Department of Medicine, University \\ Hospital of Padova, Padova, Italy
}

Correspondence: Gian Paolo Fadini Department of Medicine, University of Padova, Via Giustiniani 2, 35100 Padova, Italy

Tel $+3904982 I 4318$

Fax +39049821 2184

Email gianpaolo.fadini@unipd.it

\begin{abstract}
Type 2 diabetes is characterized by a progressive decline in beta cell function, with consequent worsening of glycemic control. The ideal antihyperglycemic treatment should achieve good and sustained glycemic control, with a low risk of hypoglycemia and no weight gain. This paper reviews the efficacy and tolerability of liraglutide, a glucagon-like peptide-1 receptor agonist approved for the treatment of type 2 diabetes. Once-daily injection of liraglutide (at doses of $1.2 \mathrm{mg}$ and $1.8 \mathrm{mg}$ ), as monotherapy or in combination with one or two oral antihyperglycemic agents, was associated with greater improvements in glycemic control compared with active comparators or placebo in several controlled, randomized Phase III trials, including the six trials of the LEAD (Liraglutide Effect and Action in Diabetes) program. Liraglutide also improved beta cell function, body weight, systolic blood pressure, and lipid profile, thereby achieving many of the goals of ideal antihyperglycemic therapy. Liraglutide was generally well tolerated in the Phase III trials. The most common adverse events were nausea, vomiting, and diarrhea, usually of mild to moderate intensity. The observed rate of pancreatitis was low and comparable with that of the general diabetic population. In conclusion, although most trials were relatively short and focused on surrogate endpoints, liraglutide emerges as an effective and well tolerated treatment for type 2 diabetes, carrying a low risk of hypoglycemia, weight loss, and possible reduction of cardiovascular risk.
\end{abstract}

Keywords: body weight, hypoglycemia, cardiovascular, incretin

\section{Introduction to type 2 diabetes control}

The prevalence and incidence of type 2 diabetes are increasing worldwide, in conjunction with increased obesity rates and unhealthy lifestyles. It has been estimated that 366 million people worldwide will develop type 2 diabetes by $2030 .{ }^{1}$ Chronic hyperglycemia leads to microvascular (retinopathy, neuropathy, renal failure) and macrovascular (ischemic heart and cerebrovascular disease, lower limb ischemia) complications. It also increases the risk of other disabling conditions, such as cognitive decline and cancer, leading to excess morbidity and mortality. ${ }^{2}$ The economic cost of type 2 diabetes is mainly related to treatment of its complications, and heavily burdens health care systems. ${ }^{3}$

It is well established that the risk of chronic complications is related to level of glycemia, as measured by glycated hemoglobin $\left(\mathrm{HbA}_{1 \mathrm{c}}\right)^{2}{ }^{2}$ The American Diabetes Association and the European Association for the Study of Diabetes recommend lowering $\mathrm{HbA}_{1 \mathrm{c}}$ to $<7.0 \%(53 \mathrm{mmol} / \mathrm{mol})$ to reduce the risk of microvascular complications, but this target is not universally valid for all patients. ${ }^{4}$ The UK Prospective Diabetes Study 10-year follow-up has shown the long-term benefit of early good glycemic 
control on the risk of ischemic heart disease in patients with newly diagnosed type 2 diabetes..$^{5}$ On the other hand, three large randomized controlled trials (Action to Control Cardiovascular Risk in Diabetes [ACCORD], ${ }^{6}$ Action in Diabetes and Vascular Disease: Preterax and Diamicron Modified-Release Controlled Evaluation [ADVANCE], ${ }^{7}$ Veterans Affairs Diabetes Trial [VADT] $),{ }^{8}$ evaluated the effect of strict versus conventional glycemic control on cardiovascular events in patients with well-established type 2 diabetes and high cardiovascular risk. None of these studies showed a significant reduction in cardiovascular endpoints in the group receiving intensive treatment. The ACCORD trial was prematurely terminated, owing to an excess of cardiovascular mortality in the intensive treatment group, possibly related to a three-fold higher rate of hypoglycemia. The results of the aforementioned trials suggest that it is important to individualize glycemic targets according to the clinical history and characteristics of each patient. ${ }^{9}$ More stringent targets $\left(\mathrm{HbA}_{1 \mathrm{c}} 6.0 \%-6.5 \%\right)$ can be considered for selected patients with a short disease duration, low risk of hypoglycemia, no cardiovascular disease, and long life expectancy. Conversely, less aggressive targets $\left(\mathrm{HbA}_{1 \mathrm{c}}\right.$ $7.5 \%-8.5 \%$ ) should be applied for elderly patients with a long disease duration, advanced complications, a high risk of hypoglycemia, and/or limited life expectancy. ${ }^{4}$

The pathogenesis of type 2 diabetes is the consequence of a progressive loss of pancreatic beta cell function combined with increasing peripheral insulin resistance. ${ }^{10}$ It has been estimated that only $50 \%$ of normal beta cell function is still present at the time of diagnosis. ${ }^{11}$ In addition, pancreatic alpha cells hypersecrete glucagon, promoting hepatic glucose output. ${ }^{12}$ Impairment of glucose homeostasis is often associated with atherogenic dyslipidemia, elevated blood pressure, and central obesity in the context of the metabolic syndrome. ${ }^{13}$ All these conditions recognize insulin resistance as the underlying factor, and lead to a two-fold increased risk of cardiovascular disease. ${ }^{14}$

The management of type 2 diabetes is complex and should be extended beyond glycemic control, aiming to preserve beta cell function and to control the concomitant cardiovascular risk factors. Metformin is considered the first-line therapy for type 2 diabetes in addition to lifestyle modifications. ${ }^{4}$ The progressive decline in beta cell function often leads to secondary failure of metformin monotherapy and leads to the need for other antihyperglycemic drugs. The traditional noninsulin antihyperglycemic agents (sulfonylureas, thiazolidinediones, alpha-glucosidase inhibitors) show similar efficacy in reducing $\mathrm{HbA}_{1 \mathrm{c}}(0.7 \%-1.0 \%)$, but are all associated with considerable side effects, such as hypoglycemia and weight gain, among others. ${ }^{15}$ Incretin-based therapies, including dipeptidyl peptidase-4 inhibitors (DPP-4) and glucagon-like peptide-1 receptor agonists (GLP-1 analogs), are relatively new antihyperglycemic agents that significantly improve glycemic control without hypoglycemia or weight gain. ${ }^{16}$ Liraglutide, a GLP-1 receptor agonist, causes significant improvements in $\mathrm{HbA}_{1 \mathrm{c}}$ and weight, with a low risk of hypoglycemia compared with other therapies, and has potentially favorable effects on cardiovascular risk, the lipid profile, and blood pressure. This review summarizes the available efficacy and safety data for liraglutide, mainly focusing on Phase III clinical trials. Data from real world clinical practice are also discussed.

\section{Native GLP-I and incretin-based therapies}

Incretins are gut hormones released in the circulation in response to oral ingestion of glucose. The two major incretins are GLP-1 and glucose-dependent insulinotropic polypeptide. ${ }^{17}$ They play a crucial role in glucose homeostasis by enhancing pancreatic insulin secretion when glucose is taken orally (incretin effect) and by suppressing glucagon release and hepatic glucose output. ${ }^{18}$ Both GLP-1 and glucose-dependent insulinotropic polypeptide are rapidly inactivated by DPP-4. GLP-1 has also been shown to delay gastric emptying and to improve beta cell, as well as endothelial and cardiac function. Patients with type 2 diabetes display an impaired incretin effect, which makes the use of incretinergic medications attractive, although native GLP-1 cannot be used because of its short half-life. Two classes of incretin-based therapies are now available, ie, GPL-1 analogs (eg, exenatide and lixisenatide) or receptor agonists (eg, liraglutide) and DPP-4 inhibitors. ${ }^{19}$ The former are produced by recombinant DNA technology and are resistant to DPP-4 degradation. The latter (such as sitagliptin, vildagliptin, saxagliptin, linagliptin, and alogliptin) prolong the half-life of endogenous GLP-1 by preventing its enzymatic degradation.

\section{Pharmacology, mode of action, pharmacokinetics of liraglutide Pharmacodynamic properties}

Liraglutide is an acylated GLP-1 analog produced by recombinant DNA technology, in which the lysine at position 34 is replaced with arginine, and a palmitic fatty acid chain is added to lysine at position 26. These modifications allow liraglutide to share $97 \%$ homology with endogenous human GLP-1, compared with the $57 \%$ sequence identity 
of exenatide. Liraglutide binds to the GLP-1 receptor, a G-protein coupled receptor located on the membrane cell surface, and activates an intracellular cascade resulting in an increase of cyclic adenosine monophosphate. Liraglutide influences the secretion of both pancreatic beta and alpha cells. The most important effect is the glucose-dependent stimulation of insulin secretion that lowers blood glucose concentrations while protecting against hypoglycemia. Liraglutide also reduces glucagon secretion by pancreatic alpha cells, and consequently hepatic glucose production. Data from preclinical studies have demonstrated that liraglutide may increase beta cell mass and function by both stimulating replication and inhibiting apoptosis. ${ }^{20,21}$ In animal models of type 2 diabetes in $(\mathrm{db} / \mathrm{db})$ mice and Zucker diabetic fatty rats, liraglutide significantly increased beta cell mass and proliferation rate in comparison with vehicle. ${ }^{22,23} \mathrm{In}$ an in vitro study of human pancreatic islet cells, liraglutide promoted beta cell proliferation and inhibited interleukin$1 \beta$-induced apoptosis after 4 days of incubation. ${ }^{24}$ These observations are of particular interest in the treatment of type 2 diabetes, given that progressive islet dysfunction is considered the main determinant of hyperglycemia. In addition, liraglutide delays gastric emptying and acid secretion, thus reducing post-prandial hyperglycemia and increasing satiety. Binding to GLP-1 receptors in the central nervous system (area postrema and subfornical organ) results in increased satiety and reduced food intake. It has been shown that liraglutide can improve cognitive function, reduce amyloid plaque deposition, and enhance long-term synaptic transmission when injected for 2 months in Amyloid protein P-presenilin 1 mice (a model of dementia), suggesting a possible preventive effect in the early stages of Alzheimer's disease. ${ }^{25}$ Liraglutide also provides clinically significant weight loss, ${ }^{26}$ improves myocardial ${ }^{27}$ and endothelial ${ }^{28}$ function, and ameliorates lipid and blood pressure profiles.

\section{Pharmacokinetic properties}

The half-life of liraglutide has been estimated to be 13 hours, allowing for once-daily administration. For comparison, the half-life of native GLP-1 is about 1.5-2.0 minutes and the halflife of exenatide is 4-6 hours. ${ }^{29}$ After subcutaneous injection, the fatty acid side chain allows liraglutide to self-associate, forming heptamers at the injection site. The size of the heptamers and the bond strength of self-association slow down absorption from the depot site into the bloodstream. As a result, liraglutide is absorbed slowly, achieving maximum plasma concentrations 8-12 hours after subcutaneous injection. Once in the bloodstream, the fatty acid forms reversible bonds with serum albumin, provides resistance to DPP-4, and reduces renal clearance. ${ }^{30}$ Systemic exposure to liraglutide is doserelated, and peak liraglutide concentrations and area under the concentration-time curve increase proportionally over the $0.6-1.8 \mathrm{mg}$ dose range. After subcutaneous administration of liraglutide $0.6 \mathrm{mg}$, the mean apparent volume of distribution is $13 \mathrm{~L}$. Pharmacokinetic studies failed to identify a specific excretory organ, suggesting liraglutide could be metabolized in a way similar to that of large proteins. Small studies in patients with type 2 diabetes suggest that the pharmacokinetic profile of liraglutide is not altered in subjects with renal ${ }^{31}$ or hepatic ${ }^{32}$ impairment. No relevant interactions have been noted between liraglutide $1.8 \mathrm{mg}$ and coadministration of single doses of drugs metabolized via cytochrome P450. ${ }^{33}$

\section{Efficacy studies}

The therapeutic efficacy of once-daily liraglutide at doses of $0.6,1.2$, and $1.8 \mathrm{mg}$ as monotherapy or in combination with one or two oral antidiabetic agents has been evaluated in numerous Phase III trials. The vast majority of these trials were relatively short, sponsored by the manufacturer, and focused on surrogate endpoints. The LEAD (Liraglutide Effect and Action in Diabetes) program included six randomized controlled trials (Figure 1), and enrolled about 6,500 patients recruited from more than 600 sites across 41 countries worldwide (Table 1). ${ }^{34-39}$ General inclusion criteria were type 2 diabetes, age $18-80$ years, baseline $\mathrm{HbA}_{1 \mathrm{c}}$ $7 \%-10 \%$ (or $7 \%-11 \%$ ), and body mass index $<45 \mathrm{~kg} / \mathrm{m}^{2}$. Patients were ineligible in the following cases: previous insulin therapy, hepatic or renal impairment, uncontrolled hypertension $(>180 / 100 \mathrm{mmHg}$ ), clinically significant cardiovascular disease, or cancer. The demographic characteristics of patients are cumulatively listed in Table 2 . LEAD- ${ }^{34}$ (liraglutide + glimepiride versus rosiglitazone + glimepiride) and LEAD-2 ${ }^{35}$ (liraglutide + metformin versus glimepiride + metformin) compared the effect of the association of liraglutide with one oral antidiabetic drug versus two oral antidiabetic drugs. LEAD- $3^{36}$ compared the efficacy of liraglutide as monotherapy versus glimepiride. LEAD- $4^{37}$ evaluated the combination of liraglutide with two oral antidiabetic drugs (metformin + rosiglitazone) versus standard therapy (metformin + rosiglitazone). LEAD- $5^{38}$ compared association therapy of liraglutide with two oral antidiabetic drugs (metformin + glimepiride) versus insulin glargine plus two oral antidiabetic drugs (metformin + glimepiride). Finally, LEAD- $6^{39}$ compared the efficacy and safety of liraglutide (plus metformin \pm sulfonylureas) with exenatide (plus metformin \pm sulfonylureas). The duration of the studies 


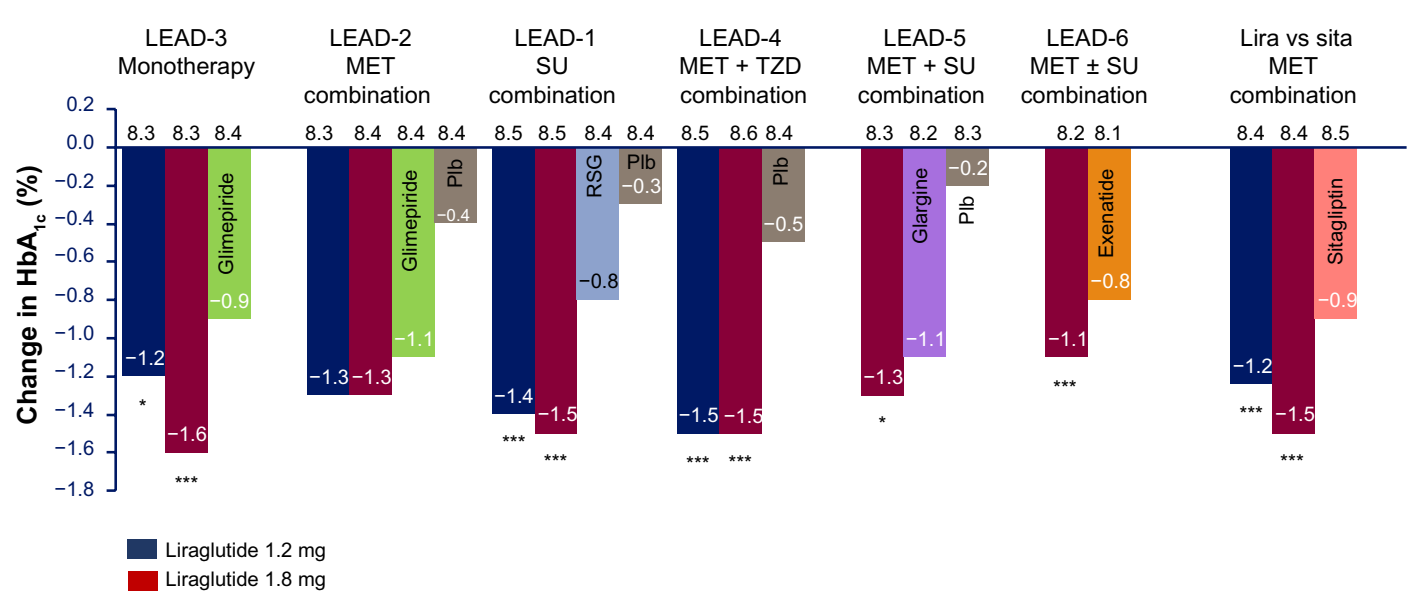

Figure I Summary of the glycemic efficacy of liraglutide in the LEAD program.

Notes: Baseline $\mathrm{HbA}_{\mathrm{Ic}}$ values are shown at the top of each column, with absolute $\mathrm{HbA}(\%)$ reductions shown at the bottom of each column. $* P<0.0 \mathrm{I}$ and $* * * P<0.000 \mathrm{I}$ versus active comparator.

Abbreviations: MET, metformin; SU, sulfonylureas; TZD, thiazolidinediones; Sita, sitagliptin; Plb, placebo; HbA Action in Diabetes program; sita, sitagliptin; Lira, liraglutide; vs, versus; RSG, rosiglitazone.

was 26 weeks, except for LEAD- $3,{ }^{36}$ which was extended to 52 weeks. The primary outcome was change in $\mathrm{HbA}_{1 \mathrm{c}}$ from baseline. Secondary outcomes included the proportion of patients reaching $\mathrm{HbA}_{1 \mathrm{c}}$ targets $<7.0 \%$, changes in fasting and post-prandial plasma glucose, body weight, beta cell function, blood pressure, and lipid profile.

\section{Effect on $\mathrm{HbA}_{\mathrm{Ic}}$}

Liraglutide alone or in combination with oral antidiabetic drugs was shown to be able to reduce $\mathrm{HbA}_{1 \mathrm{c}}$ more than active comparators in all of the LEAD trials, ${ }^{34-39}$ except LEAD-2. ${ }^{35}$ The efficacy of liraglutide as monotherapy has been evaluated in LEAD- $3^{36}$ in patients with early stage type 2 diabetes previously treated with lifestyle modifications or with a single oral antidiabetic drug at a dose that was $<50 \%$ of the maximum approved dose. Liraglutide monotherapy reduced $\mathrm{HbA}_{1 \mathrm{c}}$ from baseline by $-0.84 \%$ and $-1.14 \%$ at doses of $1.2 \mathrm{mg}$ and $1.8 \mathrm{mg}$, respectively, compared with a $-0.51 \%$ reduction in the glimepiride group. The greatest reduction in $\mathrm{HbA}_{1 \mathrm{c}}(-1.6 \%)$ was observed in the subgroup of subjects previously treated only with diet or exercise at the dose of $1.8 \mathrm{mg}$. Only LEAD- $2^{35}$ did not show significant differences in $\mathrm{HbA}_{1 \mathrm{c}}$ reduction between liraglutide $1.2 \mathrm{mg}$ and $1.8 \mathrm{mg}$ and glimepiride, both administered in association with metformin $(-1.3 \%$ versus $-1.2 \%)$. In LEAD $6,{ }^{39}$ the mean reduction in $\mathrm{HbA}_{1 \mathrm{c}}$ levels was significantly higher with liraglutide $1.8 \mathrm{mg}$ once daily than with exenatide $10 \mathrm{mg}$ twice daily $(-1.12 \%$ versus $-0.79 \%, P<0.0001)$.

In all LEAD trials, ${ }^{34,36-39}$ except for LEAD- $2,{ }^{35}$ the proportion of subjects who achieved the American Diabetes Association target of $\mathrm{HbA}_{1 \mathrm{c}}<7.0 \%$ at the end of follow-up was significantly higher with liraglutide as monotherapy or in combination with oral antidiabetic drugs when compared with active comparators. In the LEAD-3 trial, ${ }^{36}$ a higher percentage of patients not previously treated with oral antidiabetic drugs reached the target recommended by the American Diabetes Association compared with previously treated subjects, suggesting that liraglutide monotherapy should be more effective than other oral antidiabetic drugs in the early stages of diabetes.

\section{Effect on fasting and post-prandial plasma glucose}

In the LEAD-1, LEAD-2, LEAD-3, and LEAD-4 studies, ${ }^{34-37}$ liraglutide reduced fasting plasma glucose from baseline up to $43 \mathrm{mg} / \mathrm{dL}(2.4 \mathrm{mmol} / \mathrm{L})$, which was greater than the decrease observed with active comparators (up $32 \mathrm{mg} / \mathrm{dL}$ $[1.8 \mathrm{mmol} / \mathrm{L}])$. In the LEAD-3 trial, ${ }^{36}$ fasting plasma glucose levels decreased during the first 2 weeks of treatment with liraglutide and by week 4 in the glimepiride group. Compared with glimepiride, patients treated with liraglutide $1.2 \mathrm{mg}$ or $1.8 \mathrm{mg}$ had a significantly greater decline from baseline of fasting plasma glucose at 52 weeks $(-15 \mathrm{mg} / \mathrm{dL}[-0.84 \mathrm{mmol} / \mathrm{L}]$ for liraglutide $1.2 \mathrm{mg},-26 \mathrm{mg} / \mathrm{dL}$ [ $-1.42 \mathrm{mmol} / \mathrm{L}]$ for liraglutide $1.8 \mathrm{mg},-4.7 \mathrm{mg} / \mathrm{dL}[-0.29 \mathrm{mmol} / \mathrm{L}]$ for glimepiride, $P=0.027$ and $P=0.0001$ versus glimepiride, respectively). In LEAD-5, ${ }^{38}$ liraglutide compared with insulin glargine did not show a greater reduction in fasting plasma glucose when both treatments were associated with metformin and glimepiride. Finally, in the LEAD-6 study, ${ }^{39}$ the reduction of fasting plasma glucose from baseline was significantly greater with liraglutide than with exenatide $(-29.0 \mathrm{mg} / \mathrm{dL}[-1.61 \mathrm{mmol} / \mathrm{L}]$, 
Table I Summary of design details, treatment regimens, and changes of primary endpoint from baseline of Phase III trials of the LEAD program

\begin{tabular}{|c|c|c|c|c|c|}
\hline Study & Design & $\begin{array}{l}\text { Duration } \\
\text { (weeks) }\end{array}$ & Treatment & Patients (n) & $\begin{array}{l}\text { HbA }_{1 c} \% \\
\text { Mean (SD) }\end{array}$ \\
\hline \multirow[t]{7}{*}{ LEAD-I } & $\mathrm{DB}, \mathrm{DD}, \mathrm{PC}$ & 26 & Glimepiride (2-4 mg) & Total I,04I & \\
\hline & $\mathrm{AC}, \mathrm{MC}$ & & + & & \\
\hline & & & Liraglutide $0.6 \mathrm{mg}$ & 233 & $-0.60(1.1)^{* .8}$ \\
\hline & & & Liraglutide $1.2 \mathrm{mg}$ & 228 & $-1.08(1.1)^{\S . \#}$ \\
\hline & & & Liraglutide $1.8 \mathrm{mg}$ & 234 & $-1.13(1.1)^{\S . \#}$ \\
\hline & & & Rosiglitazone $4 \mathrm{mg}$ & 232 & $-0.44(\mathrm{I} . \mathrm{I})$ \\
\hline & & & Placebo & 114 & $+0.23(0.7)$ \\
\hline \multirow[t]{7}{*}{ LEAD-2 } & $\mathrm{DB}, \mathrm{DD}, \mathrm{PC}$ & 26 & Metformin I g BID & Total I,09। & \\
\hline & $\mathrm{AC}, \mathrm{MC}, \mathrm{MN}$ & & + & & \\
\hline & & & Liraglutide $0.6 \mathrm{mg}$ & 242 & $-0.69(1.1)^{\S}$ \\
\hline & & & Liraglutide $1.2 \mathrm{mg}$ & 241 & $-0.97(1.1)^{\S}$ \\
\hline & & & Liraglutide $1.8 \mathrm{mg}$ & 242 & $-1.00(1.1)^{\S}$ \\
\hline & & & Glimepiride $4 \mathrm{mg}$ & 244 & $-0.98(1.1)$ \\
\hline & & & Placebo & 122 & $+0.09(1.0)$ \\
\hline \multirow[t]{5}{*}{ LEAD-3 } & DB, DD, PC, & 52 & Diet/exercise & Total 746 & \\
\hline & $\mathrm{AC}, \mathrm{MC}$ & & + & & \\
\hline & & & Liraglutide $1.2 \mathrm{mg}$ & 251 & $-0.84(1.2)^{\varsigma}$ \\
\hline & & & Liraglutide $1.8 \mathrm{mg}$ & 247 & $-1.14(1.2)^{\#}$ \\
\hline & & & Glimepiride 8 mg & 248 & $-0.5 \mid(1.2)$ \\
\hline \multirow[t]{5}{*}{ LEAD-4 } & $\mathrm{DB}, \mathrm{PC}$ & 26 & Metformin I g BID and & Total 533 & \\
\hline & AC, MC & & $\begin{array}{l}\text { rosiglitazone } 4 \mathrm{mg} \text { BID } \\
+\end{array}$ & & \\
\hline & & & Liraglutide $1.2 \mathrm{mg}$ & 178 & $-1.5(1.0)^{\S}$ \\
\hline & & & Liraglutide $1.8 \mathrm{mg}$ & 178 & $-1.5(1.0)^{\S}$ \\
\hline & & & Placebo & 177 & $-0.5(1.0)$ \\
\hline \multirow[t]{5}{*}{ LEAD-5 } & $\mathrm{DB} / \mathrm{NB}, \mathrm{PC}$ & 26 & Metformin I g BID & Total 58I & \\
\hline & $A C, M C$ & & $\begin{array}{l}\text { and glimepiride } 4 \mathrm{mg} / \text { day } \\
+\end{array}$ & & \\
\hline & & & Liraglutide 1.8 mg & 232 & $-1.33(1.4)^{5.45}$ \\
\hline & & & Insulin glargine & 234 & $-1.09(1.4)$ \\
\hline & & & Placebo & 115 & $-0.24(1.2)$ \\
\hline \multirow[t]{4}{*}{ LEAD-6 } & $\mathrm{NB}, \mathrm{AC}$ & 26 & Metformin and/or SU & Total 464 & \\
\hline & $\mathrm{MC}, \mathrm{MN}$ & & + & & \\
\hline & & & Liraglutide $1.8 \mathrm{mg}$ & 233 & $-1.12(1.2)^{\S}$ \\
\hline & & & Exenatide $10 \mu \mathrm{g}$ BID & 231 & $-0.79(\mathrm{I} .2)$ \\
\hline
\end{tabular}

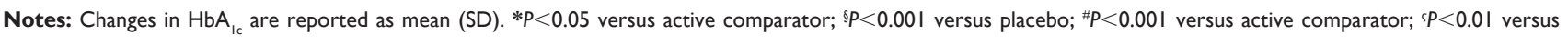
active comparator.

Abbreviations: BID, twice daily; LEAD, Liraglutide Effect and Action in Diabetes; HbA , glycosylated hemoglobin; SU, sulfonylurea; DB, double-blind; DD, double-dummy; PC, placebo-controlled; MC, multicenter; MN, multinational; NB, nonblind; SD, standard deviation; AC, active comparator.

versus $-10.8 \mathrm{mg} / \mathrm{dL}[-0.60 \mathrm{mmol} / \mathrm{L}], P<0.0001)$. During the 14-week extension (week 26-40) of the LEAD-6 trial, ${ }^{40}$ switching of treatment from exenatide to liraglutide allowed a further fasting plasma glucose reduction of $16 \mathrm{mg} / \mathrm{dL}$ ( $0.9 \mathrm{mmol} / \mathrm{L})$. Improvement of postprandial glucose was significant in the LEAD-1, LEAD-2, LEAD-3, LEAD-4, and LEAD-5 trials, ${ }^{34-38}$ but not in the LEAD-6 trial, ${ }^{39}$ as liraglutide was less effective than exenatide in lowering postprandial glucose at breakfast and dinner.

\section{Effect on beta cell function}

Results from Phase III trials, ${ }^{34} 41$ in line with previous preclinical and Phase II data, indirectly support a beneficial effect of liraglutide treatment on beta cell function, as measured by homeostasis model assessment for beta cell function analysis (HOMA-B), and by the proinsulin to insulin ratio. ${ }^{42,43} \mathrm{~A}$ metaanalysis of all LEAD trials confirmed a significant improvement of HOMA-B at 26 weeks in liraglutide-treated patients compared with rosiglitazone, exenatide, and placebo. ${ }^{44}$ The HOMA-B improvement for liraglutide $1.2 \mathrm{mg}$ and $1.8 \mathrm{mg}$ was $31.7 \%$ and $35.7 \%$, respectively, compared with $9.5 \%$ for rosiglitazone $(P<0.05), 5.7 \%$ for exenatide $(P<0.0001)$, and $7.5 \%$ for placebo $(P<0.0001)$. Glimepiride treatment in combination with metformin led also to an improvement of $31.8 \%$. Decreases in the proinsulin to insulin ratio from baseline were significantly greater for liraglutide $(1.2 \mathrm{mg}$ 
Table 2 Patient demographics and baseline characteristics of the Phase III LEAD program

\begin{tabular}{|c|c|c|c|c|c|c|c|}
\hline Study & Arm of treatment (n) & Age (years) & $\begin{array}{l}\text { Sex } \\
\text { (M/F)\% }\end{array}$ & $\begin{array}{l}\text { Duration of } \\
\text { diabetes (years) }\end{array}$ & $\mathrm{HbA}_{\mathrm{Ic}}(\%)$ & $\begin{array}{l}\text { FPG } \\
(\mathrm{mmol} / \mathrm{L})\end{array}$ & $\begin{array}{l}\text { Body mass } \\
\text { index }\left(\mathrm{kg} / \mathrm{m}^{2}\right)\end{array}$ \\
\hline \multirow[t]{5}{*}{ LEAD- I $^{34}$} & Liraglutide $0.6 \mathrm{mg}(\mathrm{n}=233)$ & $55.7(9.9)$ & $54 / 56$ & $7.7(5.5)$ & $8.4(1.0)$ & $10.0(2.4)$ & $30.0(5.0)$ \\
\hline & Liraglutide $1.2 \mathrm{mg}(\mathrm{n}=228)$ & $57.7(9.0)$ & $45 / 55$ & $8.1(5.5)$ & $8.5(1.1)$ & $9.8(2.7)$ & $29.8(5.1)$ \\
\hline & Liraglutide $1.8 \mathrm{mg}(\mathrm{n}=234)$ & $55.6(10.0)$ & $53 / 47$ & $7.8(5.6)$ & $8.5(0.9)$ & $9.7(2.4)$ & $30.0(5.1)$ \\
\hline & Placebo $(n=1 \mid 4)$ & $54.7(10.0)$ & $47 / 53$ & $8.0(5.6)$ & $8.4(1.0)$ & $9.5(2.0)$ & $30.3(5.4)$ \\
\hline & Rosiglitazone 4 mg ( $\mathrm{n}=232)$ & $56.0(9.8)$ & $47 / 53$ & $7.8(5.3)$ & $8.4(1.0)$ & $9.9(2.5)$ & $29.4(4.8)$ \\
\hline \multirow[t]{5}{*}{ LEAD-2 ${ }^{35}$} & Liraglutide $0.6 \mathrm{mg}(\mathrm{n}=242)$ & $56(11.0)$ & $62 / 38$ & $7(5.0)$ & $8.4(0.9)$ & $10.2(2.4)$ & $30.5(4.8)$ \\
\hline & Liraglutide $1.2 \mathrm{mg}(\mathrm{n}=24 \mathrm{I})$ & $57(9.0)$ & $54 / 46$ & $7(5.0)$ & $8.3(1.0)$ & $9.9(2.3)$ & $31.1(4.8)$ \\
\hline & Liraglutide $1.8 \mathrm{mg}(\mathrm{n}=242)$ & $57(9.0)$ & $59 / 41$ & $8(5.0)$ & $8.4(1.0)$ & $10.1(2.3)$ & $30.9(4.6)$ \\
\hline & Glimepiride 4 mg $(n=244)$ & $57(9.0)$ & $57 / 43$ & $8(5.0)$ & $8.4(1.0)$ & $10.0(2.6)$ & $31.2(4.6)$ \\
\hline & Placebo $(n=122)$ & $56(9.0)$ & $60 / 40$ & $8(6.0)$ & $8.4(1.1)$ & $10.0(2.3)$ & $31.6(4.4)$ \\
\hline \multirow[t]{3}{*}{ LEAD-3 $3^{36}$} & Liraglutide $1.2 \mathrm{mg}(\mathrm{n}=25 \mathrm{I})$ & $53.7(11.0)$ & $47 / 53$ & $5.2(5.5)$ & $8.3(1.0)$ & $9.3(2.6)$ & $33.2(5.6)$ \\
\hline & Liraglutide $1.8 \mathrm{mg}(\mathrm{n}=247)$ & $52.0(10.8)$ & $49 / 51$ & $5.3(5.1)$ & $8.3(1.1)$ & $9.5(2.6)$ & $32.8(6.3)$ \\
\hline & Glimepiride $8 \mathrm{mg}(\mathrm{n}=248)$ & $53.4(10.9)$ & $54 / 46$ & $5.6(5.1)$ & $8.4(1.2)$ & $9.5(2.6)$ & $33.2(5.6)$ \\
\hline \multirow[t]{3}{*}{ LEAD- $4^{37}$} & Liraglutide $1.2 \mathrm{mg}(\mathrm{n}=\mid 78)$ & $55(10.0)$ & $57 / 43$ & $9(6.0)$ & $8.5(1.2)$ & I0.I (2.4) & $33.2(5.4)$ \\
\hline & Liraglutide $1.8 \mathrm{mg}(\mathrm{n}=178)$ & $55(11.0)$ & $51 / 49$ & $9(6.0)$ & $8.6(1.2)$ & $10.3(2.4)$ & $33.5(5.1)$ \\
\hline & Placebo $(n=\mid 77)$ & $55(10.0)$ & $62 / 38$ & $9(6.0)$ & $8.4(1.2)$ & $10.0(2.6)$ & $33.9(5.2)$ \\
\hline \multirow[t]{3}{*}{ LEAD $-5^{38}$} & Liraglutide $1.8 \mathrm{mg}(\mathrm{n}=232)$ & $57.6(9.5)$ & $57 / 43$ & $9.2(5.8)$ & $8.3(0.9)$ & $9.1(2.1)$ & $30.4(5.3)$ \\
\hline & Placebo $(n=|| 5)$ & $57.5(9.6)$ & $49 / 51$ & $9.4(6.2)$ & $8.3(0.9)$ & $9.4(2.0)$ & $31.3(5.0)$ \\
\hline & Insulin glargine $(n=234)$ & $57.5(10.5)$ & $60 / 40$ & $9.7(6.4)$ & $8.2(0.9)$ & $9.1(2.0)$ & $30.3(5.3)$ \\
\hline \multirow[t]{2}{*}{ LEAD- $6^{39}$} & Liraglutide $1.8 \mathrm{mg}(\mathrm{n}=233)$ & $56.3(9.8)$ & $49 / 51$ & $8.5(6.2)$ & $8.2(1.0)$ & $9.8(2.5)$ & $32.9(5.5)$ \\
\hline & Exenatide $10 \mu \mathrm{g}$ bid $(\mathrm{n}=23 \mathrm{I})$ & $57.1(10.8)$ & $55 / 45$ & $7.9(5.9)$ & $8.1(1.0)$ & $9.5(2.4)$ & $32.9(5.7)$ \\
\hline
\end{tabular}

Notes: Data are reported as the mean (SD), except for sex ratio (\%).

Abbreviations: $\mathrm{HbA}_{1 \mathrm{c}}$, glycosylated hemoglobin; FPG, fasting plasma glucose; LEAD, Liraglutide Effect and Action in Diabetes; SD, standard deviation; M, male; F, female; bid, twice daily.

and $1.8 \mathrm{mg}$ ) compared with the rosiglitazone and glimepiride groups ( -0.077 and -0.08 for liraglutide $1.2 \mathrm{mg}$ and $1.8 \mathrm{mg}$, respectively, versus -0.024 for glimepiride and -0.024 for rosiglitazone, $P<0.0001) .{ }^{44}$ The reduction of the proinsulin to insulin ratio was similar between liraglutide-treated and exenatide-treated patients. ${ }^{39}$

\section{Effect on body weight}

Liraglutide significantly reduced body weight from baseline in all Phase III trials, ${ }^{34-39}$ mainly by a reduction in central fat. The weight loss was dose-dependent and, as expected, greater in people with a higher body mass index at baseline. Liraglutide $1.2 \mathrm{mg}$ and $1.8 \mathrm{mg}$ monotherapy was associated with a mean $2.1 \mathrm{~kg}$ and $2.5 \mathrm{~kg}$ weight reduction, respectively, compared with a mean $1.1 \mathrm{~kg}$ weight gain with glimepiride $(P<0.001) .{ }^{36}$ Such weight loss occurred in the first 16 weeks of treatment, and was sustained over the extended follow-up (52 weeks). There were no significant differences in weight loss between patients who had prolonged nausea (more than 7 days), and those with no nausea or nausea lasting less than 7 days. These data suggest that weight loss was independent of gastrointestinal adverse events. Mean waist circumference in the liraglutide groups was significantly reduced from baseline compared with glimepiride $(3.0 \mathrm{~cm}$ for liraglutide $1.2 \mathrm{mg}$, $3.6 \mathrm{~cm}$ for liraglutide $1.8 \mathrm{mg}$ versus $0.4 \mathrm{~cm}$ for glimepiride,
$P<0.0001)$. Generally, subjects treated with liraglutide 1.8 mg experienced more weight loss than those treated with liraglutide $1.2 \mathrm{mg}$. As expected, a higher baseline body mass index was associated with greater weight loss in all the treatment groups. There were no significant differences in weight loss between liraglutide and exenatide (both combined with metformin \pm sulfonylureas). ${ }^{39}$ In a small subgroup of the LEAD-2 trial, absolute and relative changes in total body fat mass and lean tissue mass were assessed by dual-energy X-ray absorptiometry, while visceral and subcutaneous adiposity were evaluated by computed tomography. ${ }^{35}$ Liraglutide reduced both absolute and relative fat mass more than lean mass, while glimepiride increased both types of tissues. Dose-dependent reductions from baseline of $0.7 \mathrm{~kg}, 1.6 \mathrm{~kg}$, and $2.4 \mathrm{~kg}$ for total fat mass, and of $0.5 \%, 1.1 \%$, and $1.2 \%$ for relative fat mass were observed in the $0.6 \mathrm{mg}, 1.2 \mathrm{mg}$, and $1.8 \mathrm{mg}$ liraglutide arms, respectively. Such decreases in fat mass were mainly related to a reduction in visceral adipose tissue.

\section{Effect on blood pressure and lipid profile}

Liraglutide significantly decreased systolic blood pressure from baseline in all Phase III trials..$^{34-41}$ The mean reductions in systolic blood pressure from baseline achieved at 26 weeks were $2.59 \mathrm{mmHg}(P=0.0008)$ and $2.49 \mathrm{mmHg}(P=0.003)$ 
for liraglutide $1.2 \mathrm{mg}$ and $1.8 \mathrm{mg}$, respectively, compared with $0.24 \mathrm{mmHg}(P=0.7828)$ for placebo. ${ }^{45}$ Maximum reduction of systolic blood pressure was observed when liraglutide was associated with metformin and rosiglitazone in LEAD-1 (-6.7 $\mathrm{mmHg}$ for $1.8 \mathrm{mg}$ and $-5.5 \mathrm{mmHg}$ for 1.2 $\mathrm{mg}){ }^{34}$ Reductions in systolic blood pressure occurred during the first 2 weeks of treatment and were sustained over time (26 weeks). ${ }^{45}$ Systolic blood pressure reduction was independent of weight $\operatorname{loss}^{46}$ and concomitant antihypertensive regimen. ${ }^{47}$ In addition to the beneficial effects on systolic blood pressure, liraglutide appears to significantly improve levels of total cholesterol, low-density lipoprotein cholesterol, free fatty acids, and triglycerides compared with active comparators. Total cholesterol levels decreased from baseline by $0.13 \mathrm{mmol} / \mathrm{L}$ after liraglutide treatment, compared with a 0.05 $\mathrm{mmol} / \mathrm{L}$ reduction for glimepiride and exenatide and a 0.29 $\mathrm{mmol} / \mathrm{L}$ increase with rosiglitazone. Low-density lipoprotein levels decreased from baseline by $0.20 \mathrm{mmol} / \mathrm{L}$ after liraglutide treatment, compared with a $0.12 \mathrm{mmol} / \mathrm{L}$ reduction for glimepiride, $0.15 \mathrm{mmol} / \mathrm{L}$ reduction for exenatide, and a 0.06 $\mathrm{mmol} / \mathrm{L}$ increase for rosiglitazone. ${ }^{48}$ Treatment with liraglutide for 26 weeks significantly reduced high sensitivity C-reactive protein $(-23.1 \%)$ and brain natriuretic peptide $(-11.9 \%)$, two established biomarkers of cardiovascular risk. ${ }^{48}$

\section{Comparative studies with other incretin-based therapies Liraglutide versus exenatide}

The LEAD-6 trial $^{39}$ was designed to compare the efficacy and safety of once-daily liraglutide administration with twice-daily exenatide injection, both added to background therapy with metformin and sulfonylureas. Compared with twice-daily exenatide $10 \mu \mathrm{g}$, a single daily injection of $1.8 \mathrm{mg}$ liraglutide was associated with greater reduction in $\mathrm{HbA}_{1 \mathrm{c}}(-0.79 \%$ versus $-1.12 \%, P<0.001)$ and fasting plasma glucose $(0.60 \mathrm{mmol} / \mathrm{L}$ versus $1.61 \mathrm{mmol} / \mathrm{L}, P<0.001)$. More patients achieved the American Diabetes Association target of $\mathrm{HbA}_{1 \mathrm{c}}<7.0 \%$ when treated with liraglutide 1.8 mg compared with exenatide (54\% versus $43 \%, P=0.0015)$. However, better postprandial glucose control was achieved with exenatide compared with liraglutide after breakfast and dinner (meals at which exenatide is administered) but not after lunch. Liraglutide was also associated with greater improvements in beta cell function, as measured by HOMA-B (32.1\% versus $3.0 \%, P<0.0001)$. The extent of weight loss was comparable between the two treatment groups. Less frequent minor hypoglycemia episodes and less persistent nausea were observed with liraglutide compared with exenatide. All patients who completed the 26-week LEAD- $6{ }^{39}$ trial entered a 14 -week extension phase, ${ }^{40}$ where subjects previously treated with exenatide were switched to liraglutide. Switching from exenatide to liraglutide resulted in a significant improvement in glucose control; $\mathrm{HbA}_{1 \mathrm{c}}$ and fasting plasma glucose dropped by $0.3 \%$ and $0.9 \mathrm{mmol} / \mathrm{L}$, respectively, and the proportion of patients reaching the target of $\mathrm{HbA}_{1 \mathrm{c}}<7.0 \%$ increased from $47 \%$ to $54 \%$. Moreover, patients switched to liraglutide showed a $15 \%$ improvement in beta cell function (HOMA-B), a $0.9 \mathrm{~kg}$ further weight loss, and a $3.8 \mathrm{mmHg}$ reduction in systolic blood pressure. These data confirm the superiority of liraglutide $1.8 \mathrm{mg}$ compared with exenatide with regard to global diabetes control.

\section{Liraglutide versus sitagliptin: LIRA-DPP-4i study}

Liraglutide at doses of $1.2 \mathrm{mg}$ and $1.8 \mathrm{mg}$ was compared with once-daily sitagliptin $100 \mathrm{mg}$ in a 26-week, randomized, open-label trial including patients with inadequately controlled type 2 diabetes $\left(\mathrm{HbA}_{1 \mathrm{c}} 7.5 \%-10 \%\right)$ on metformin (more than 1,500 $\mathrm{mg}$ for more than 3 months). ${ }^{41,49}$ Liraglutide $1.2 \mathrm{mg}$ and $1.8 \mathrm{mg}$ were associated with greater reductions in $\mathrm{HbA}_{1 \mathrm{c}}$ compared with sitagliptin $(-1.2 \%$ and $-1.5 \%$ versus $-0.9 \%$, respectively). Significantly more patients achieved the $\mathrm{HbA}_{1 \mathrm{c}}$ target of $<7.0 \%$ with liraglutide than with sitagliptin $(50.3 \%$ and $63.3 \%$ for $1.2 \mathrm{mg}$ and $1.8 \mathrm{mg}$ versus $27.1 \%, P<0.0001)$. After 26 weeks, the mean fasting plasma glucose reduction was significantly greater with liraglutide than with sitagliptin $(-2.14 \mathrm{mmol} / \mathrm{L}$ and -1.87 $\mathrm{mmol} / \mathrm{L}$ for $1.2 \mathrm{mg}$ and $1.8 \mathrm{mg}$ versus $-0.83 \%, P<0.0001)$. Liraglutide appeared to increase beta cell function more than sitagliptin, as measured by HOMA-B (27\%-29\% versus $4 \%, P<0.0001)$. Furthermore, liraglutide was associated with greater body weight reduction $(-2.9 \mathrm{~kg}$ to $-3.4 \mathrm{~kg}$ versus $-1.0 \mathrm{~kg}, P<0.0001)$ and overall treatment satisfaction, despite the injectable route of administration. Nausea was more frequent with liraglutide $(27 \%$ of patients on $1.8 \mathrm{mg}$ and $21 \%$ on $1.2 \mathrm{mg}$ ) than with sitagliptin (5\%). The rate of minor hypoglycemia was low (5\%), and was similar for both groups.

\section{Tolerability and safety Gastrointestinal adverse events}

Liraglutide as monotherapy or in combination with oral antidiabetic drugs was generally well tolerated in all the Phase III trials. ${ }^{34-39}$ The most common adverse events were gastrointestinal in nature (most frequently nausea, vomiting, and diarrhea), of mild intensity, and tended to decrease after 3-4 weeks of 
treatment. In LEAD-3, ${ }^{36}$ gastrointestinal adverse events were observed in $54 \%$ and $53 \%$ of patients treated with liraglutide $1.2 \mathrm{mg}$ and $1.8 \mathrm{mg}$, respectively, compared with $28 \%$ on glimepiride. The corresponding rates of nausea were $29 \%$, $31 \%$, and $9 \%$, respectively. No significant dose-response relationship was observed. In LEAD- $6,{ }^{39}$ the initial incidence of nausea was similar between the liraglutide and exenatide groups; however, it was less persistent with liraglutide at 26 weeks. Overall rates of withdrawal because of nausea and vomiting were $1.5 \%-2.8 \%$ across the LEAD trials.

\section{Hypoglycemia}

Across the LEAD trials program, ${ }^{34} 41$ the overall rate of hypoglycemic events observed in patients with type 2 diabetes treated with liraglutide was generally low. The rates of minor hypoglycemia with liraglutide $1.2 \mathrm{mg}$ and $1.8 \mathrm{mg}$ monotherapy was eight times lower than with glimepiride ( 0.22 and 0.21 versus 1.76 events per patient per year). ${ }^{36}$ Combination therapy of liraglutide with metformin or with rosiglitazone was associated with a greater reduction in minor hypoglycemic events compared with comparators ( 0.03 to 1.9 versus 0.13 events per patient per year for metformin, and 0.02 to 0.04 versus 0.03 events per patient per year for rosiglitazone). ${ }^{37}$ An increased risk of minor hypoglycemic episodes was observed for liraglutide added to sulfonylureas (1.1 events per patient per year). ${ }^{34,38,39}$ No major hypoglycemic events were reported in the LEAD-2, LEAD-3, LEAD-4, and LEAD-6 trials. ${ }^{35-37}$ LEAD- ${ }^{34}$ reported one major hypoglycemic episode for liraglutide $1.8 \mathrm{mg}$ in association with glimepiride, and LEAD-5 $5^{38}$ reported six major hypoglycemic events, of which only one required medical treatment.

\section{C-cell cancer}

Medullary thyroid carcinoma is a rare form of C-cell thyroid tumor, with an incidence ranging from 0.10 to 0.22 cases per 100,000 person-years. ${ }^{50}$ In the liraglutide preclinical trials, thyroid cancer was observed in rats and in two female mice. ${ }^{51,52}$ Studies in monkeys did not find any hyperplasia, adenoma, or carcinoma derived from C-cells after longterm exposure to high doses of liraglutide ( $5 \mathrm{mg} / \mathrm{kg} /$ day $).{ }^{51}$ None of the patients treated with liraglutide in clinical trials (LEAD-1 to LEAD-6 and LIRA-DPP-4i) developed thyroid cancer or any increase in calcitonin levels compared with active comparators. ${ }^{3441}$ The higher rate of thyroid cancer in rodents could be related to the larger number of $\mathrm{C}$-cells, which are very sensitive to GLP-1 stimulation. Conversely, humans and monkeys have a lower density of C-cells, which are insensitive to GLP-1 stimulation, as confirmed by serum calcitonin determination. The utility of calcitonin screening in liraglutide-treated patients is still debated. ${ }^{53}$ The American Association of Clinical Endocrinology, in agreement with the US Food and Drug Administration (FDA), does not recommend monitoring of liraglutide-treated patients using serum calcitonin or thyroid ultrasound, because it is still unknown if this would mitigate any hypothetical risk of thyroid tumors in humans. ${ }^{54}$ The American Association of Clinical Endocrinology and FDA contraindicate the use of liraglutide in patients with a personal or family history of medullary thyroid carcinoma and in patients with multiple endocrine neoplasia syndrome type $2 .{ }^{54}$

\section{Pancreatitis}

Compared with healthy subjects, diabetic patients have an up to three-fold higher incidence of acute pancreatitis $(0.5-5.6$ events per 1,000 person-years). ${ }^{55}$ In preclinical studies in rodents and monkeys, liraglutide did not induce biochemical or histopathological features of pancreatitis or pancreatic cancer, even when exposure levels were up to 60 times higher than the maximal clinical dose for humans. ${ }^{56,57}$ Few cases of acute pancreatitis were observed among patients treated with liraglutide across all Phase I-III clinical trials. ${ }^{58}$ Eight cases were reported in liraglutide-treated patients compared with one case in active comparators, corresponding to an incidence of 1.6 versus 0.7 events per 1,000 subject-years $(P<0.94)$. This incidence is low and within the predicted range for the diabetic population. ${ }^{58}$ There are too few cases to confirm whether or not there is a cause-effect relationship between treatment with liraglutide and pancreatitis. The FDA and European Medicines Agency suggest to avoid use of liraglutide in patients with a personal history of pancreatitis and to discontinue treatment if pancreatitis is suspected. ${ }^{59}$ Concerns have been raised regarding the possibility that incretin therapy in humans results in increased proliferation of the exocrine compartment and increases the risk for development of neuroendocrine tumors. ${ }^{60}$ In preclinical studies in monkeys, up to 87 weeks of treatment with liraglutide did not cause an increase in pancreatic weight nor development of pancreatic tumors. During Phase III trials, two cases of pancreatic cancer were diagnosed in patients randomized to liraglutide (one of which was detected after 1 week of treatment). During post-marketing surveillance, the pancreatic cancer reporting rate was approximately 0.05 events per 1,000 patient-years over the period 2009-2013, suggesting no relationship between cumulative exposure and risk (data on file). ${ }^{61}$ 


\section{Immunogenicity}

In all 26 week Phase III trials, treatment with liraglutide was associated with a low incidence of antibody formation $(<8.6 \%)$ due to the high amino acid homology with human endogenous GLP-1. ${ }^{62}$ The anti-liraglutide antibodies did not appear to reduce the glucose-lowering efficacy of liraglutide, and tended to decrease over time. ${ }^{62}$ Conversely, treatment with exenatide was associated with higher incidence of antibody development (up to $43 \%$ ), resulting in decreased efficacy. ${ }^{63}$

\section{Safety in patients with renal impairment}

Meta-analysis of the six Phase III trials $(n=3,927)$ investigated the efficacy and safety of liraglutide in patients with type 2 diabetes and normal (estimated glomerular filtration rate [eGFR] $>90 \mathrm{~mL}$ per minute), mildly (eGFR 60-89 mL per minute), moderately (eGFR $31-59 \mathrm{~mL}$ per minute), and severely (eGFR $<30 \mathrm{~mL}$ per minute) impaired renal function. ${ }^{34,64}$ Mild renal impairment had no effect on $\mathrm{HbA}_{1 \mathrm{c}}$-lowering or weight loss in liraglutide-treated patients when compared with placebo. Liraglutide was safe and well tolerated in mild renal impairment when compared with placebo, and there were no significant differences in rates of minor hypoglycemia, acute renal failure, or nausea. Nausea was reported more frequently in patients with moderate or severe renal impairment (eGFR $<60 \mathrm{~mL}$ per minute) treated with liraglutide compared with those with normal or mild renal impairment, and the effect was dose-dependent. ${ }^{64}$ The European Medicines Agency recommends avoiding the use of liraglutide in patients with moderate to severe impaired renal function, because there is limited relevant therapeutic experience.

\section{Patient-focused perspectives}

One of the most widely used satisfaction measures in diabetes is the Diabetes Treatment Satisfaction Questionnaire, which consists of two versions, ie, a status version (DTSQ) and a change version (DTSQc). ${ }^{65}$ The DTSQ comprises six individual items, ie, satisfaction with current treatment, convenience, flexibility, understanding of diabetes, willingness to continue, and willingness to recommend treatment to others. Each item is scored from 0 (very dissatisfied/inconvenient) to 6 (very satisfied/very convenient). Together, these are summed to form a total treatment satisfaction score, which ranges from 0 to 36 , where higher scores indicate greater satisfaction with treatment. The frequencies of hyperglycemia and hypoglycemia are measured separately, with scores from 0 (none of the time, perceived low frequency) to 6 (most of the time, perceived high frequency). The Impact of Weight on Quality of Life-Lite questionnaire is a 31-item self-report measure examining obesity-specific quality of life, and scores from 0 (worst outcome) to 100 (best outcome). ${ }^{66}$ Four studies evaluated treatment satisfaction and patient-reported outcomes in type 2 diabetics treated with liraglutide, compared with glimepiride, sitagliptin, and exenatide. In the 26-week LEAD-2 trial, ${ }^{35}$ improvement in patient satisfaction with liraglutide plus metformin after 26 weeks was similar to that with glimepiride plus metformin and significantly higher than that with metformin monotherapy. ${ }^{67}$ Recipients of liraglutide perceived a significantly lower rate of hypoglycemia compared with patients receiving glimepiride plus metformin, and a higher incidence of hyperglycemia than subjects on metformin monotherapy. Liraglutide also induces greater weight loss, but a higher incidence of nausea compared with glimepiride. In the 52-week LEAD- $3^{36}$ study ( $n=746$ ), liraglutide (both $1.2 \mathrm{mg}$ and $1.8 \mathrm{mg}$ ) showed improvements in glycemic control, a decrease in body weight, and a lower incidence of hypoglycemia than glimepiride. The study used a self-administered questionnaire comprising a battery of 77 questions related to weight perception, body image, and health-related quality of life. All participants completed the questionnaire at baseline, and at weeks 28 and 52. The LEAD-3 test battery indicated that both liraglutide doses $(1.2 \mathrm{mg}$ and $1.8 \mathrm{mg}$ ) were associated with more favorable perceptions of body weight, and patients using liraglutide $1.8 \mathrm{mg}$ were $52 \%$ less likely to feel overweight. ${ }^{68}$ In the 26 -week LIRA-DPP-4i study, liraglutide led to a greater reduction in $\mathrm{HbA}_{1 \mathrm{c}}$ and weight loss than sitagliptin, with a similarly low risk of hypoglycemia. Overall treatment satisfaction at week 26 improved significantly more in the liraglutide $1.8 \mathrm{mg}$ group than in the sitagliptin group, with significant differences on the following items: satisfaction with current treatment $(P=0.01)$, likelihood of continuing $(P=0.01)$, likelihood of recommending treatment to others $(P=0.003)$. Differences between the two liraglutide groups $(1.2 \mathrm{mg}$ and $1.8 \mathrm{mg}$ ) and between liraglutide $1.2 \mathrm{mg}$ and sitagliptin were not statistically significant. Hyperglycemia was perceived less frequently with liraglutide than with sitagliptin $(P<0.01)$, while the subjective feeling of hypoglycemia was similar across groups. ${ }^{69}$ In the extension of the study up to 78 weeks, participants who switched from sitagliptin to liraglutide $\left(1.2 \mathrm{mg}\right.$ and $1.8 \mathrm{mg}$ ) showed a further reduction in $\mathrm{HbA}_{1 \mathrm{c}}$ and weight loss, resulting in a greater improvement of total treatment satisfaction. ${ }^{70}$ These data are important because they show similar levels of satisfaction with injected and oral agents, suggesting that improved treatment efficacy and weight loss may overcome the potential reluctance of diabetic 
patients to use injectable therapies. In the 26-week LEAD-6 trial, ${ }^{39}$ patients using liraglutide experienced a significantly greater decrease in $\mathrm{HbA}_{1 \mathrm{c}}$, a lower rate of hypoglycemia, and less persistent nausea compared with exenatide. After 26 weeks, overall treatment satisfaction on the DTSQ was higher in liraglutide-treated patients than in exenatide-treated patients (DTSQ $>24$ in $91 \%$ versus $82 \%, P=0.02$ ). Treatment satisfaction improved significantly in patients receiving exenatide who switched to liraglutide during the extension phase up to week $40(P=0.003)$, remaining stable in those continuing liraglutide. ${ }^{71}$

\section{Real world data}

There are important and significant differences in the setting of randomized controlled clinical trials (RCTs) compared with the real world clinical setting, which can limit transferability of RCT results to the everyday treatment of type 2 diabetes. RCTs are well controlled, well documented, and regularly followed up, while in the real world the prescription algorithms are different, the follow-up scheme is dictated by local practices, and cost/availability constrains apply. In addition, patients in RCTs are highly selected (relatively limited numbers, motivated, well instructed in drug use, with good compliance and limited comorbidities) and may be different from the general population of type 2 diabetics in the everyday setting, who are likely to have multiple comorbidities. For these reasons, the importance of comparing data coming from RCTs with observational clinical data is increasingly recognized.

In an Italian cohort of 166 patients who initiated liraglutide based on clinical decision and were followed for up to 16 weeks (average age 57 years, 61\% male, mean body mass index $36.3 \mathrm{~kg} / \mathrm{m}^{2}$, disease duration 7.8 years [range 1-24]), the maximal $\mathrm{HbA}_{1 \mathrm{c}}$ reduction was $1.5 \% \pm$ $0.3 \%$ and the proportion of patients achieving the target $\mathrm{HbA}_{1 \mathrm{c}}$ of $<7 \%$ was up to $50 \%$ at the most commonly used dose of $1.2 \mathrm{mg}$. The maximal decrease in body weight was $4.0 \pm 0.9 \mathrm{~kg}$. Importantly, most patients displayed a simultaneous reduction of $\mathrm{HbA}_{1 \mathrm{c}}$ and weight loss, with $24.7 \%$ reaching both the target of $\mathrm{HbA}_{1 \mathrm{c}}<7.0 \%$ and weight loss of $<5 \%$ initial body weight. ${ }^{72}$ This figure is similar to that shown by Zinman et $\mathrm{al}^{73}$ in a comparative assessment, in which liraglutide $1.2 \mathrm{mg}$ and $1.8 \mathrm{mg}$ were superior to other treatments for type 2 diabetes in the proportion of patients reaching the combined endpoint of $\mathrm{HbA}_{1 \mathrm{c}}<7.0 \%$ and no weight loss. In search of the clinical determinant of glycemic efficacy and weight loss, it was found that, as expected, the major predictor of drop in $\mathrm{HbA}_{1 \mathrm{c}}$ was baseline $\mathrm{HbA}_{1 \mathrm{c}}$ and the major predictor of weight loss was baseline body mass index. Interestingly, glycemic efficacy was unrelated to baseline body mass index and weight reduction was unrelated to baseline $\mathrm{HbA}_{1 \mathrm{c}}$; glycemic efficacy and body weight reduction were also unrelated, possibly suggesting different mechanisms of action. The $\mathrm{HbA}_{1 \mathrm{c}}$ reduction has been shown to be greater in insulin-naïve patients and in those with a diabetes duration of less than 5 years, although also still relevant in long-standing diabetes. ${ }^{72}$

As a further example of real world data, a study from the Association of British Clinical Diabetologists found similar results, in that the only determinants of glycemic efficacy and body weight reduction were, respectively, baseline $\mathrm{HbA}_{1 \mathrm{c}}$ and body mass index. In addition, although liraglutide was slightly more effective in patients with a disease duration of less than 5 years, the $\mathrm{HbA}_{1 \mathrm{c}}$ reduction was still $>1 \%$ in patients with a disease duration of more than 10 years. Indeed, the antihyperglycemic regimen (number of medications and insulin usage) seems to be a more reliable indicator of the stage of disease and eventual glycemic response to liraglutide compared with disease duration per se. ${ }^{74}$

The strong similarities between these two real world experiences with liraglutide in different geographic locations confirm the clinical validity of data extracted from the LEAD trial program, which seem to be transferable to clinical practice.

\section{Conclusion and place in therapy}

The American Diabetes Association and European Association for the Study of Diabetes consensus guidelines recommend to lower $\mathrm{HbA}_{1 \mathrm{c}}$ to $<7 \%$ if this target can be achieved without significant hypoglycemia and body weight gain. ${ }^{4}$ Although lifestyle interventions are considered the first step in the management of type 2 diabetes, a pharmacological therapy is usually required to cope with the progressive worsening of glycemic control. Metformin is currently considered the first-line therapy, in addition to lifestyle modifications. If the $\mathrm{HbA}_{1 \mathrm{c}}$ target is not achieved after 3 months, addition of a second antihyperglycemic agent is recommended. Sulfonylureas, thiazolidinediones, basal insulin, and incretin-based drugs (both GLP-1 receptor agonists and DPP-4 inhibitors) can all be considered as a second-line therapy. Both sulfonylureas and insulin are associated with increased risk of hypoglycemia and weight gain. ${ }^{15}$ Thiazolidinediones are associated with fluid retention, weight gain, and increased risk of cardiac failure and bone fractures. Incretin-based therapies, ie, DPP-4 inhibitors and GLP-1 receptor agonists, have been shown to significantly improve glycemic control with a low risk of hypoglycemia and without weight gain. ${ }^{15}$ Liraglutide is a 


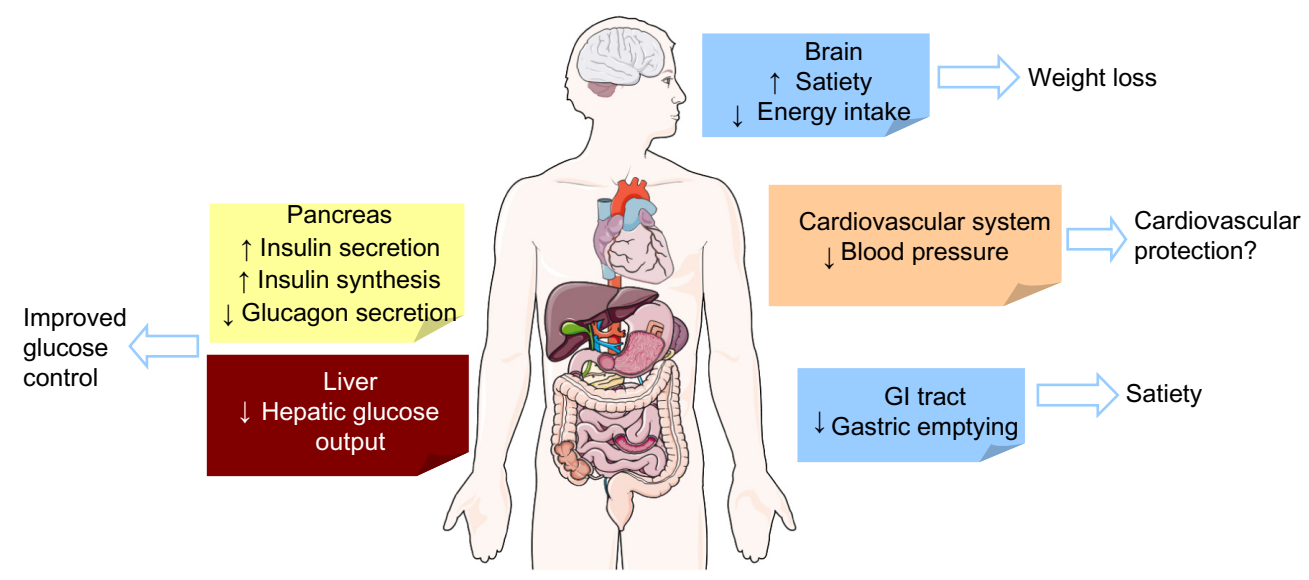

Figure 2 Schematic representation of the effects of the glucagon-like peptide-I receptor agonist, liraglutide, in type 2 diabetes. Abbreviation: $\mathrm{Gl}$, gastrointestinal.

once-daily GLP-1 analog with 97\% homology to human native GLP-1. In Phase III clinical trials, liraglutide as monotherapy and in combination with oral antidiabetic drugs was associated with significant and sustained improvement of glycemic control, as measured by $\mathrm{HbA}_{1 \mathrm{c}}$, fasting plasma glucose, and postprandial glucose. ${ }^{34-39}$ The overall rate of hypoglycemic events in liraglutide-treated patients was generally low unless combined with sulfonylureas. Liraglutide has been suggested to have extraglycemic effects, including the well documented reduction of body weight and blood pressure. In addition, although less well demonstrated, liraglutide seems to improve beta cell function and to reduce total and lowdensity lipoprotein cholesterol and triglyceride levels. Such pleiotropic effects contribute to considering liraglutide as a first-tier choice after metformin monotherapy. Treatment with liraglutide is thus able to improve typical features of the metabolic syndrome, suggesting a protective effect on cardiovascular risk. ${ }^{48}$ This is being investigated in the ongoing LEADER (Liraglutide Effect and Action in Diabetes: Evaluation of Cardiovascular Outcomes Results) trial. A schematic representation of the mechanism of action of liraglutide is shown in Figure 2.

The most common adverse events associated with liraglutide are gastrointestinal, are of mild intensity, and tend to vanish after 3 weeks of treatment. Safety concerns have been raised during the development and post-marketing experience with liraglutide; a small number of cases of pancreatitis have been reported, ${ }^{58}$ while the initial concerns regarding thyroid C-cell tumors have not been confirmed in humans. ${ }^{51}$ Nonetheless, attention should be paid to such very rare but potentially life-threatening side effects, and the choice of liraglutide should be weighed against the safety profile of other diabetic therapies.
It should be acknowledged that most of the efficacy trials for liraglutide were relatively short (1 year or less), sponsored by the manufacturer, and based on surrogate endpoints, such as $\mathrm{HbA}_{1 \mathrm{c}}$ and glucose profiles. Although the post-marketing experience is growing, we are still awaiting the results of trials focused on hard endpoints, such as LEADER. Meanwhile, we have discussed herein how data from the real world clinical setting suggest that improvements in glucose control and body weight are similar to what is observed in Phase III trials, thus strengthening the role for this medication in the management of type 2 diabetes.

In conclusion, liraglutide is an effective and well tolerated option for the management of type 2 diabetes, has a low risk of hypoglycemia, achieves sustained weight loss, and decreases cardiovascular risk factors. In accordance with the American Diabetes Association/European Association for the Study of Diabetes consensus guidelines, liraglutide should be considered as an add-on therapy in patients not controlled on metformin monotherapy.

\section{Disclosure}

GPF has received lecture or consultancy fees from AstraZeneca, Bristol-Meyer-Squibb, Eli Lilly, Novo Nordisk, and Sanofi-Aventis. The authors have no other conflicts of interest in this work.

\section{References}

1. Wild S, Roglic G, Green A, Sicree R, King H. Global prevalence of diabetes: estimates for the year 2000 and projections for 2030. Diabetes Care. 2004;27(5): 1047-1053.

2. Stratton IM, Adler AI, Neil HA, et al. Association of glycaemia with macrovascular and microvascular complications of type 2 diabetes (UKPDS 35): prospective observational study. BMJ. 2000;321(7258): $405-412$. 
3. Sicras-Mainar A, Navarro-Artieda R, Ibanez-Nolla J. Clinical and economic characteristics associated with type 2 diabetes. Rev Clin Esp. December 17, 2013. [Epub ahead of print.]

4. Inzucchi SE, Bergenstal RM, Buse JB, et al. Management of hyperglycaemia in type 2 diabetes: a patient-centered approach. Position Statement of the American Diabetes Association (ADA) and the European Association for the Study of Diabetes (EASD). Diabetologia. 2012;55(6):1577-1596.

5. Holman RR, Paul SK, Bethel MA, Matthews DR, Neil HA. 10-year follow-up of intensive glucose control in type 2 diabetes. N Engl J Med. 2008;359(15):1577-1589.

6. Gerstein HC, Miller ME, Byington RP, et al; Action to Control Cardiovascular Risk in Diabetes Study Group. Effects of intensive glucose lowering in type 2 diabetes. N Engl J Med. 2008;358(24):2545-2559.

7. Patel A, MacMahon S, Chalmers J, et al; ADVANCE Collaborative Group. Intensive blood glucose control and vascular outcomes in patients with type 2 diabetes. N Engl J Med. 2008;358(24):2560-2572.

8. Duckworth W, Abraira C, Moritz T, et al. Glucose control and vascular complications in veterans with type 2 diabetes. $N$ Engl J Med. 2009;360(2):129-139.

9. Turnbull FM, Abraira C, Anderson RJ, et al; Control Group. Intensive glucose control and macrovascular outcomes in type 2 diabetes. Diabetologia. 2009;52(11):2288-2298.

10. Ferrannini E, Gastaldelli A, Miyazaki Y, Matsuda M, Mari A, DeFronzo RA. Beta-cell function in subjects spanning the range from normal glucose tolerance to overt diabetes: a new analysis. $J$ Clin Endocrinol Metab. 2005;90(1):493-500.

11. [No authors listed]. UK Prospective Diabetes Study 16. Overview of 6 years' therapy of type II diabetes: a progressive disease. UK Prospective Diabetes Study Group. Diabetes. 1995;44(11):1249-1258.

12. Nauck MA. Incretin-based therapies for type 2 diabetes mellitus: properties, functions, and clinical implications. Am J Med. 2011; 124(Suppl 1):S3-S18.

13. Ford ES, Giles WH, Mokdad AH. Increasing prevalence of the metabolic syndrome among US adults. Diabetes Care. 2004;27(10): 2444-2449.

14. Mottillo S, Filion KB, Genest J, et al. The metabolic syndrome and cardiovascular risk - a systematic review and meta-analysis. $J$ Am Coll Cardiol. 2010;56(14):1113-1132.

15. Kahn SE, Haffner SM, Heise MA, et al. Glycemic durability of rosiglitazone, metformin, or glyburide monotherapy. $N$ Engl J Med. 2006;355(23):2427-2443.

16. Cernea S, Raz I. Therapy in the early stage: incretins. Diabetes Care. 2011;34 Suppl 2:S264-S271.

17. Baggio LL, Drucker DJ. Biology of incretins: GLP-1 and GIP. Gastroenterology. 2007;132(6):2131-2157.

18. Nauck M, Stockmann F, Ebert R, Creutzfeldt W. Reduced incretin effect in type 2 (non-insulin-dependent) diabetes. Diabetologia. 1986;29(1):46-52.

19. Drucker DJ, Nauck MA. The incretin system: glucagon-like peptide-1 receptor agonists and dipeptidyl peptidase-4 inhibitors in type 2 diabetes. Lancet. 2006;368(9548):1696-1705.

20. Knudsen LB, Nielsen PF, Huusfeldt PO, et al. Potent derivatives of glucagon-like peptide-1 with pharmacokinetic properties suitable for once daily administration. J Med Chem. 2000;43(9):1664-1669.

21. Montanya E, Sesti G. A review of efficacy and safety data regarding the use of liraglutide, a once-daily human glucagon-like peptide 1 analogue, in the treatment of type 2 diabetes mellitus. Clin Ther. 2009;31(11): 2472-2488.

22. Sturis J, Gotfredsen CF, Romer J, et al. GLP-1 derivative liraglutide in rats with beta-cell deficiencies: Influence of metabolic state on beta-cell mass dynamics. Br J Pharmacol. 2003;140(1):123-132.

23. Rolin B, Larsen MO, Gotfredsen CF, et al. The long-acting GLP-1 derivative NN2211 ameliorates glycemia and increases beta-cell mass in diabetic mice. Am J Physiol Endocrinol Metab. 2002;283(4): E745-E752.
24. Rutti S, Sauter NS, Bouzakri K, Prazak R, Halban PA, Donath MY. In vitro proliferation of adult human beta-cells. PLoS One. 2012;7(4): e35801.

25. McClean PL, Holscher C. Liraglutide can reverse memory impairment, synaptic loss and reduce plaque load in aged APP/PS1 mice, a model of Alzheimer's disease. Neuropharmacology. 2014;76 Pt A: $57-67$.

26. Raun K, von Voss P, Gotfredsen CF, Golozoubova V, Rolin B, Knudsen LB. Liraglutide, a long-acting glucagon-like peptide-1 analog, reduces body weight and food intake in obese candy-fed rats, whereas a dipeptidyl peptidase-IV inhibitor, vildagliptin, does not. Diabetes. 2007;56(1):8-15.

27. Nikolaidis LA, Mankad S, Sokos GG, et al. Effects of glucagonlike peptide- 1 in patients with acute myocardial infarction and left ventricular dysfunction after successful reperfusion. Circulation. 2004;109(8):962-965.

28. Hattori Y, Jojima T, Tomizawa A, et al. A glucagon-like peptide-1 (GLP-1) analogue, liraglutide, upregulates nitric oxide production and exerts anti-inflammatory action in endothelial cells. Diabetologia. 2010;53(10):2256-2263.

29. Elbrond B, Jakobsen G, Larsen S, et al. Pharmacokinetics, pharmacodynamics, safety, and tolerability of a single-dose of NN2211, a long-acting glucagon-like peptide 1 derivative, in healthy male subjects. Diabetes Care. 2002;25(8):1398-1404.

30. Watson E, Jonker DM, Jacobsen LV, Ingwersen SH. Population pharmacokinetics of liraglutide, a once-daily human glucagon-like peptide-1 analog, in healthy volunteers and subjects with type 2 diabetes, and comparison to twice-daily exenatide. J Clin Pharmacol. 2010;50(8): 886-894.

31. Jacobsen LV, Hindsberger C, Robson R, Zdravkovic M. Effect of renal impairment on the pharmacokinetics of the GLP-1 analogue liraglutide. Br J Clin Pharmacol. 2009;68(6):898-905.

32. Flint A, Nazzal K, Jagielski P, Hindsberger C, Zdravkovic M. Influence of hepatic impairment on pharmacokinetics of the human GLP-1 analogue, liraglutide. Br J Clin Pharmacol. 2010;70(6):807-814.

33. Kapitza C, Zdravkovic M, Hindsberger C, Flint A. The effect of the once-daily human glucagon-like peptide 1 analog liraglutide on the pharmacokinetics of acetaminophen. Adv Ther. 2011;28(8):650-660.

34. Marre M, Shaw J, Brandle M, et al; LEAD-1 SU study group. Liraglutide, a once-daily human GLP-1 analogue, added to a sulphonylurea over 26 weeks produces greater improvements in glycaemic and weight control compared with adding rosiglitazone or placebo in subjects with type 2 diabetes (LEAD-1 SU). Diabet Med. 2009;26(3):268-278.

35. Nauck M, Frid A, Hermansen K, et al; LEAD-2 Study Group. Efficacy and safety comparison of liraglutide, glimepiride, and placebo, all in combination with metformin, in type 2 diabetes: The LEAD (liraglutide effect and action in diabetes)-2 study. Diabetes Care. 2009;32(1): 84-90.

36. Garber A, Henry R, Ratner R, et al; LEAD-3 (Mono) Study Group. Liraglutide versus glimepiride monotherapy for type 2 diabetes (LEAD-3 mono): a randomised, 52-week, Phase III, double-blind, parallel-treatment trial. Lancet. 2009;373(9662):473-481.

37. Zinman B, Gerich J, Buse JB, et al; LEAD-4 Study Investigators. Efficacy and safety of the human glucagon-like peptide-1 analog liraglutide in combination with metformin and thiazolidinedione in patients with type 2 diabetes (LEAD-4 Met+TZD). Diabetes Care. 2009;32(7): 1224-1230.

38. Russell-Jones D, Vaag A, Schmitz O, et al; Liraglutide Effect and Action in Diabetes 5 (LEAD-5) met+SU Study Group. Liraglutide vs insulin glargine and placebo in combination with metformin and sulfonylurea therapy in type 2 diabetes mellitus (LEAD- 5 met+SU): a randomised controlled trial. Diabetologia. 2009;52(10):2046-2055.

39. Buse JB, Rosenstock J, Sesti G, et al; LEAD-6 Study Group. Liraglutide once a day versus exenatide twice a day for type 2 diabetes: a 26 -week randomised, parallel-group, multinational, open-label trial (LEAD-6). Lancet. 2009;374(9683):39-47. 
40. Buse JB, Sesti G, Schmidt WE, et al; Liraglutide Effect Action in Diabetes-6 Study Group. Switching to once-daily liraglutide from twice-daily exenatide further improves glycemic control in patients with type 2 diabetes using oral agents. Diabetes Care. 2010;33(6): 1300-1303.

41. Pratley RE, Nauck M, Bailey T, et al; 1860-LIRA-DPP-4 Study Group. Liraglutide versus sitagliptin for patients with type 2 diabetes who did not have adequate glycaemic control with metformin: a 26-week, randomised, parallel-group, open-label trial. Lancet. 2010;375(9724): 1447-1456.

42. Degn KB, Juhl CB, Sturis J, et al. One week's treatment with the long-acting glucagon-like peptide 1 derivative liraglutide (NN2211) markedly improves 24-h glycemia and alpha- and beta-cell function and reduces endogenous glucose release in patients with type 2 diabetes. Diabetes. 2004;53(5):1187-1194.

43. Mattheus D, Marre M, Le Thi TD, et al. Liraglutide once daily human GLP-1 analog, significantly improves beta-cell function in subjects with type 2 diabetes. Diabetes. 2008;57:A150.

44. Matthews DR, Vilsbøll T, Courrèges J-P, Zychma M, Falahati A, Bode BW. Liraglutide improves two indicators of beta cell function HOMA-B and proinsulin:insulin ratio - in a meta-analysis of 6 clinical trials. Diabetologia. 2010;53 Suppl 1:S339.

45. Fonseca V, Falahati A, Zychma M, Madsbad S, Plutzky J. A meta-analysis of six clinical trials demonstrates that the once-daily human GLP-1 analogue liraglutide reduces systolic blood pressure. Diabetologia. 2009;52 Suppl 1:S299.

46. Fonseca VA, Henry RR, Tabanera y Palacios R, Brett J, Plutzky J. In subjects with type 2 diabetes, liraglutide, a once-daily human GLP-1 analogue, reduces systolic blood pressure with negligible impact from weight loss. Diabetologia. 2010;53 Suppl 1:S510.

47. Fonseca V, Plutzky J, Montanya E, et al. Liraglutide, a once-daily human GLP-1 analog, lowers systolic blood pressure (SBP) independently of concomitant antihypertensive treatment. Diabetes. 2010;59 Suppl 1: A79(296-OR).

48. Plutzky J, Garber AJ, Falahati A, Toft AD, Poulter NR. The once-daily human GLP-1 analogue, liraglutide, significantly reduces markers of cardiovascular risk in type 2 diabetes: a meta-analysis of six clinical trials. Eur Heart J. 2009;30 Suppl 1:917.

49. Pratley R, Nauck M, Bailey T, et al. One year of liraglutide treatment offers sustained and more effective glycaemic control and weight reduction compared with sitagliptin, both in combination with metformin, in patients with type 2 diabetes: a randomised, parallel-group, open-label trial. Int J Clin Pract. 2011;65(4):397-407.

50. Aschebrook-Kilfoy B, Ward MH, Sabra MM, Devesa SS. Thyroid cancer incidence patterns in the united states by histologic type, 1992-2006. Thyroid. 2011;21(2):125-134.

51. Bjerre Knudsen L, Madsen LW, Andersen S, et al. Glucagon-like peptide-1 receptor agonists activate rodent thyroid C-cells causing calcitonin release and C-cell proliferation. Endocrinology. 2010;151(4): 1473-1486.

52. Parks M, Rosebraugh C. Weighing risks and benefits of liraglutide the FDA's review of a new antidiabetic therapy. $N$ Engl J Med. 2010;362(9):774-777.

53. Hegedus L, Moses AC, Zdravkovic M, Le Thi T, Daniels GH. GLP-1 and calcitonin concentration in humans: lack of evidence of calcitonin release from sequential screening in over 5000 subjects with type 2 diabetes or nondiabetic obese subjects treated with the human GLP-1 analog, liraglutide. J Clin Endocrinol Metab. 2011;96(3): 853-860.

54. Costante G, Durante C, Francis Z, Schlumberger M, Filetti S. Determination of calcitonin levels in C-cell disease: clinical interest and potential pitfalls. Nat Clin Pract Endocrinol Metab. 2009;5(1): 35-44.

55. Noel RA, Braun DK, Patterson RE, Bloomgren GL. Increased risk of acute pancreatitis and biliary disease observed in patients with type 2 diabetes: a retrospective cohort study. Diabetes Care. 2009;32(5):834-838.
56. Nyborg NC, Molck AM, Madsen LW, Knudsen LB. The human GLP-1 analog liraglutide and the pancreas: evidence for the absence of structural pancreatic changes in three species. Diabetes. 2012;61(5): 1243-1249.

57. Vrang N, Jelsing J, Simonsen L, et al. The effects of 13 wk of liraglutide treatment on endocrine and exocrine pancreas in male and female ZDF rats: a quantitative and qualitative analysis revealing no evidence of drug-induced pancreatitis. Am J Physiol Endocrinol Metab. 2012;303(2):E253-E264.

58. Jensen TM, Saha K, Steinberg W. Assessment of acute pancreatitis in liraglutide type 2 diabetes trials. Pancreas. 2012;41: 1370-1371

59. European Medicines Agency; Victoza liraglutide. EPAR summary for the public. Available from: http://www.ema.europa.eu/ ema/index.jsp?curl=pages/medicines/human/medicines $/ 001026$ / human_med_001137.jsp\&mid=WC0b01ac058001d124. Accessed February 24, 2014

60. Butler AE, Campbell-Thompson M, Gurlo T, Dawson DW, Atkinson M, Butler PC. Marked expansion of exocrine and endocrine pancreas with incretin therapy in humans with increased exocrine pancreas dysplasia and the potential for glucagon-producing neuroendocrine tumors. Diabetes. 2013;62(7):2595-2604.

61. Funch D, Gydesen H, Tornoe K, Major-Pedersen A, Chan KA. A prospective, claims-based assessment of the risk of pancreatitis and pancreatic cancer with liraglutide compared with other antidiabetic drugs. Diabetes Obes Metab. 2014;16(3):273-275.

62. Buse JB, Garber A, Rosenstock J, et al. Liraglutide treatment is associated with a low frequency and magnitude of antibody formation with no apparent impact on glycemic response or increased frequency of adverse events: results from the liraglutide effect and action in diabetes (LEAD) trials. J Clin Endocrinol Metab. 2011;96(6): 1695-1702.

63. DeFronzo RA, Ratner RE, Han J, Kim DD, Fineman MS, Baron AD. Effects of exenatide (exendin-4) on glycemic control and weight over 30 weeks in metformin-treated patients with type 2 diabetes. Diabetes Care. 2005;28(5):1092-1100.

64. Davidson JA, Brett J, Falahati A, Scott D. Mild renal impairment and the efficacy and safety of liraglutide. Endocr Pract. 2011;17(3): 345-355.

65. Speight J. Assessing patient satisfaction: concepts, applications, and measurement. Value Health. 2005;8 Suppl 1:S6-S8.

66. Kolotkin RL, Crosby RD, Kosloski KD, Williams GR. Development of a brief measure to assess quality of life in obesity. Obes Res. 2001;9(2): $102-111$.

67. Hermansen K, Kolotkin RL, Hammer M, Zdravkovic M, Matthews D. Patient-reported outcomes in patients with type 2 diabetes treated with liraglutide or glimepiride, both as add-on to metformin. Prim Care Diabetes. 2010;4(2):113-117.

68. Bode BW, Testa MA, Magwire M, et al; LEAD-3 Study Group. Patientreported outcomes following treatment with the human GLP-1 analogue liraglutide or glimepiride in monotherapy: results from a randomized controlled trial in patients with type 2 diabetes. Diabetes Obes Metab. 2010;12(7):604-612.

69. Davies M, Pratley R, Hammer M, Thomsen AB, Cuddihy R. Liraglutide improves treatment satisfaction in people with type 2 diabetes compared with sitagliptin, each as an add on to metformin. Diabet Med. 2011;28(3):333-337.

70. Montanya E, Pratley R, Nauck M, et al. Switching from sitagliptin to liraglutide, in combination with metformin, improves treatment satisfaction in patients with type 2 diabetes Diabetes. 2011;60 Suppl 1: A307.

71. Schmidt WE, Christiansen JS, Hammer M, Zychma MJ, Buse JB. Patient-reported outcomes are superior in patients with type 2 diabetes treated with liraglutide as compared with exenatide, when added to metformin, sulphonylurea or both: results from a randomized, openlabel study. Diabet Med. 2011;28(6):715-723. 
72. Fadini GP, Simioni N, Frison V, et al. Independent glucose and weightreducing effects of liraglutide in a real-world population of type 2 diabetic outpatients. Acta Diabetol. 2013;50(6):943-949.

73. Zinman B, Schmidt WE, Moses A, Lund N, Gough S. Achieving a clinically relevant composite outcome of an $\mathrm{HbA}_{1 \mathrm{c}}$ of $<7 \%$ without weight gain or hypoglycaemia in type 2 diabetes: a meta-analysis of the liraglutide clinical trial programme. Diabetes Obes Metab. 2012;14(1):77-82.
74. Ryder REJ, Sen-Gupta P, Thong KY; ABCD Nationwide Liraglutide Audit Contributors. Liraglutide is effective across a range of obese body mass indices; findings from the Association of British Clinical Diabetologists $(\mathrm{ABCD})$ nationwide liraglutide audit. Poster 801 presented at the 2012 meeting of the European Association for the Study of Diabetes, October 1-5, 2012, Berlin, Germany.

\section{Publish your work in this journal}

Diabetes, Metabolic Syndrome and Obesity: Targets and Therapy is an international, peer-reviewed open-access journal committed to the rapid publication of the latest laboratory and clinical findings in the fields of diabetes, metabolic syndrome and obesity research. Original research, review, case reports, hypothesis formation, expert opinion and commentaries are all considered for publication. The manuscript management system is completely online and includes a very quick and fair peer-review system, which is all easy to use. Visit http://www.dovepress.com/testimonials.php to read real quotes from published authors. 